\title{
High human cytomegalovirus pp65 level in cardiac allografts precedes acute rejection episodes
}

\author{
Mensur Dzabic ${ }^{\#}$, Afsar Rahbar*, Monika Grudzinska, Piotr Religa and Cecilia Söderberg-Nauclér* \\ Karolinska Institutet, Department of Medicine, Centre for Molecular Medicine, Karolinska University Hospital, Sweden
}

\begin{abstract}
Cytomegalovirus (CMV) infection is a risk factor for acute and chronic rejection of transplanted organs. We evaluated, using immunohistochemistry, the presence of CMV pp65 matrix protein in cardiac allografts and its association with acute rejection. CMV pp65 was found in $83 / 88$ (94\%) endomyocardial biopsies obtained from 35 patients and the presence of CMV was confirmed in selected patients by a nested polymerase chain reaction (PCR) assay. Although no association was found between CMV pp65 levels and rejection grade, high CMV pp65 levels preceded acute rejection episodes ( $\mathrm{p}=0.001)$ indicating a possible role for CMV intra graft infection in the pathogenesis of allograft rejection.
\end{abstract}

\section{Background}

Human cytomegalovirus (CMV) establishes latency and persistence following a primary infection. In immunocompetent patients the infection is generally subclinical but it poses serious problems in immunocompromised patients. In response to a host inflammatory response, latently infected monocytes differentiate into macrophages, enabling reactivation and replication of CMV. Through its extensive immunomodulatory capacities, CMV can induce and sustain an inflammatory response, thereby prolonging the viral replication period (reviewed in [1]).

CMV infection has been associated with acute and chronic graft rejection which is believed to involve indirect immune mediated effects of CMV, since an active CMV infection within the graft is rarely detected [2]. Other long-term complications post transplantation, such as increased risk of bacterial and fungal infections, cardiovascular disease, diabetes, and malignancies have also been associated with CMV infection [1].

Various CMV mechanisms have been suggested to be involved in allograft damage. CMV can infect a range of cell types and can by lytic infection cause direct tissue damage. A majority of the over 160 proteins produced by CMV are devoted to help the virus co-exist with its host by controlling cellular and immunological functions [1]. More recently it has been shown that 751 unique CMV proteins are translated in infected cells, reflecting the complexity of this virus [3]. Importantly, CMV replication relies on inflammation, and the virus can induce an inflammatory response via induction of cyclooxygenase- 2 and expression 5-lipoxygenase [1], potentially contributing to allograft damage. Cellular differentiation, migration, proliferation, and angiogenesis, are all affected by CMV [1] and may contribute to disease pathology in the graft.

Clinical interventional studies suggest a pathophysiological role for CMV infection in cardiac allograft rejection. In several studies of pre-emptive versus prophylactic anti-CMV treatment strategies, asymptomatic CMV replication in peripheral blood had predictive value for cardiac allograft vascular pathology (CAV) [4,5], a major cause of early and late heart transplant failure. Aggressive anti-CMV prophylaxis reduces the risk of acute rejection and CAV [6]. Animal model studies have also provided support for $\mathrm{CMV}$ as a strong pathogenic cofactor in allograft rejection [7]. Although CMV infection is associated with acute and chronic rejection in organ transplant recipients, the virus has been difficult to detect in affected organs [2] and thus it is unclear whether CMV infection is causative or merely represents an epiphenomenon. Immunohistochemical analysis of tissue biopsies for infectious organisms, including CMV, has been of great value in transplant pathology [8]. In a recent study, using sensitive detection techniques, we show that CMV proteins are present in a majority of renal allografts and that high intragraft CMV protein levels are associated with reduced allograft survival [9]. In this study we sought to evaluate the presence and significance of CMV protein expression in cardiac allografts.

To address this issue, we analyzed endomyocardial biopsies of cardiac allografts for presence of the CMV pp65 matrix protein. CMV pp65 was found in a vast majority of the endomyocardial biopsies and although it did not correlate with ISHLT rejection grade, high CMV pp65 intra-graft levels more frequently preceded an acute rejection episode $(\mathrm{p}=0.001)$. Our findings support a direct role for CMV infection in allograft damage.

\section{Methods}

\section{Patients}

Eighty-six paraffin-embedded endomyocardial heart transplant

Correspondence to: Cecilia Söderberg-Nauclér, Karolinska Institutet, Department of Medicine, Centre for Molecular Medicine L8:03, Karolinska University Hospital, 17176 Stockholm, Sweden, Tel: +46 851779844; Fax: +46 8313147; E-mail: Cecilia.naucler@ki.se

\#These authors have contributed equally

Key words: cytomegalovirus, chronic rejection, acute rejection, pp65

Received: April 18, 2016; Accepted: May 02, 2016; Published: May 05, 2016 
biopsy specimens were collected from the 35 patients who received cardiac allografts at the Silesian Centre for Heart Disease in Zabrze, Poland, between 1998 and 2001 (Supplement Table 1). The mean age at transplantation was $35.7 \pm 18.3$ and 27 of the patients (77\%) were males. Congestive cardiomyopathy and ischemic heart disease were the dominating primary heart diseases affecting $43 \%$ and $34 \%$ of the patients respectively. A vast majority of the patients received a triple-drug regimen for systemic immunosuppression consisting of mycophenolate mofetil, cyclosporine A and prednisone. We did not know the CMV serological status of donors and recipients, but all patients received ganciclovir $(5 \mathrm{mg} / \mathrm{kg}$ i.v.) during the first 28 days after transplantation as CMV prophylaxis. Rejection was scored from 0 to 4: 0 - normal myocardium; 1 - focal/diffuse lymphocytic infiltrate without myocardial damage; 2 - single lymphocytic infiltrate and/or myocyte injury; 3 - diffuse/ multifocal lymphocytic infiltrates with myocyte damage or necrosis; 4 - diffuse polymorphous infiltrate with necrosis; by a pathologist in accordance with the 1990 criteria of the International Society for Heart \& Lung Transplantation (ISHLT) [10]. The ethics committee at the Karolinska University Hospital (2008/51831) approved the study.

\section{Immunohistochemistry stainings}

Paraffin sections were dewaxed, hydrated, and digested with pepsin; subjected to antigen retrieval in citrate buffer; and treated with hydrogen peroxide, avidin, biotin (DakoCytomation, Glostrop, Denmark), and Fc receptor block (Innovex Biosciences, Richmond, CA). Sections were incubated with mouse monoclonal IgG2a antibodies specific for the CMV protein pp65 (BioGenex, San Ramon CA) and with mouse monoclonal IgG2a antibodies specific for keratin 20 and von Willebrand factor (vWf) (both from DakoCytomation, Glostrop, Denmark), which also served as an isotype control. Positively stained cells were visualized with a horseradish peroxidase detection system (BioGenex, San Ramon CA) and the chromogen diaminobenzidine (Innovex Biosciences, Richmond, CA). The CMV positive cells were counted and the CMV infection level in the biopsies was scored on a five-point scale according to the percentage of CMV-positive cells among all cells: $0(0 \%), 1$ ( $\leq 25 \%), 2(26-50), 3(51-75 \%)$, and $4(\geq 75 \%)$.

\section{PCR assay}

CMV DNA was extracted with the PicoPure DNA extraction kit
(Molecular Devices, Sunnyvale, CA) and analyzed with a nested PCR assay using primers specific for the CMV major immediate-early (MIE) and pp150 genes, as described [11]. PCR products were separated on $1.5 \%$ agarose gels. The sample was considered positive if at least one of the triplicates was positive for MIE or pp150 [11].

\section{Statistical analysis}

Differences in the distribution of categorical variables were assessed using Fisher's exact test. A p value $<0.05$ was considered significant.

\section{Results}

CMV pp65 immunoreactivity was found in 83 biopsies (94\%). Inflammatory cells, small-vessel endothelial cells and cardiomyocytes were most frequently infected (Figures $1 \mathrm{~A}-1 \mathrm{~F}$ ). DNA from six biopsies from six patients, one negative and five positive for CMV pp65 by immunohistochemistry, was analyzed with a nested PCR assay. CMV MIE or pp150 was detected in all six biopsies (data not shown). CMVpositive cells were counted and the percentage of infected cells was obtained. No association was found between the CMV pp65 infection grade and ISHLT rejection grade $(\mathrm{p}=0.88)$ (Figure $2 \mathrm{~A})$.

To determine if the CMV pp65 intra-graft level is of potential prognostic value for an acute rejection episode (defined as ISHLT rejection grade $\geq 3$ ), CMV pp65 levels were compared in patients where sequential biopsies were available $(n=19)$. Nine patients experienced an acute rejection episode while ten did not. The predictive value of CMV pp65 in acute rejection biopsies was not assessed and they were excluded from the analysis. In the rejection group, in median four biopsies per patient were obtained in median over 25 months; in the non-rejection group, three biopsies per patient were obtained in median over 18 months. The CMV pp65 intra-graft levels in the biopsies just prior to an acute rejection episode were frequently higher than the CMV pp65 intra-graft levels in biopsies that were not followed by an acute rejection episode ( $\mathrm{p}=0.001$ ) (Figure $2 \mathrm{~B}$ ). The median CMV pp65 infection grade was 2 in biopsies prior to a rejection episode while the median CMV pp65 infection grade was 1 in biopsies that were not followed by an acute rejection episode.

\section{Discussion}

Our findings are consistent with the recently reported incidence of

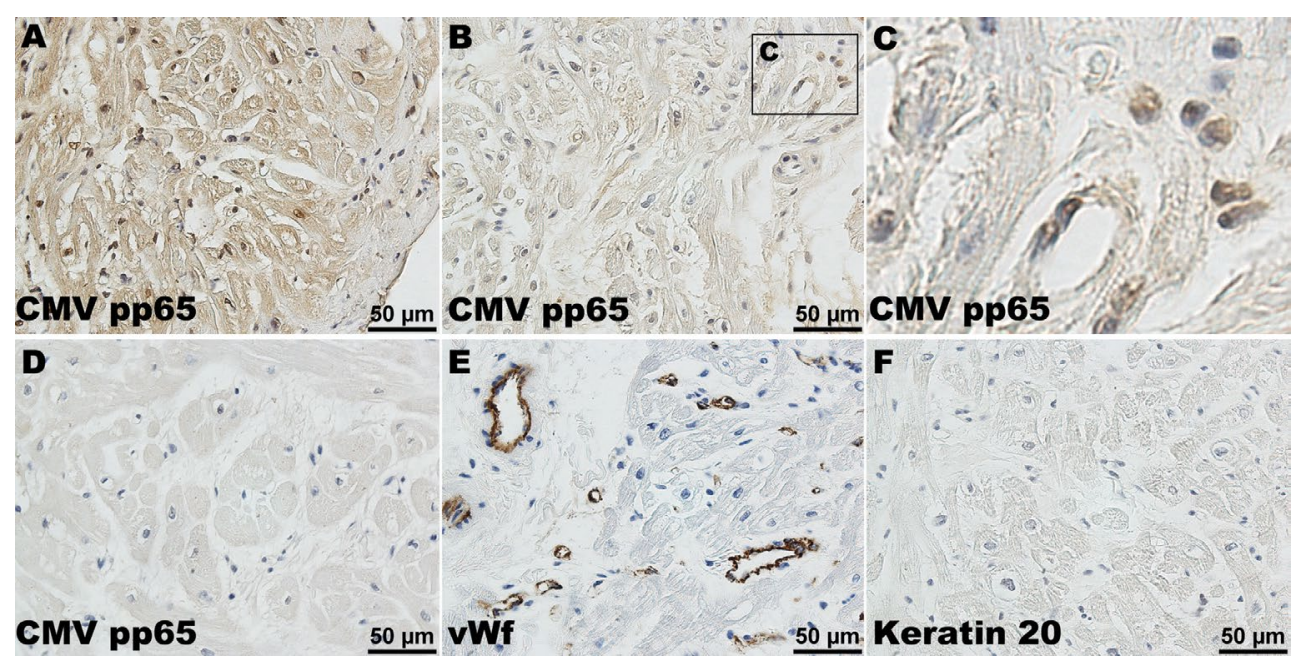

Figure 1. Endomyocardial biopsy with high (A) and low (B) CMV pp65 positivity. A magnification of the boxed area showing scattered CMV pp65 expressing cells (C). Five endomyocardial biopsies were negative for CMV pp65 (D). The positive control was vWf (E) while keratin 20 (F) was used as a negative control. 
A

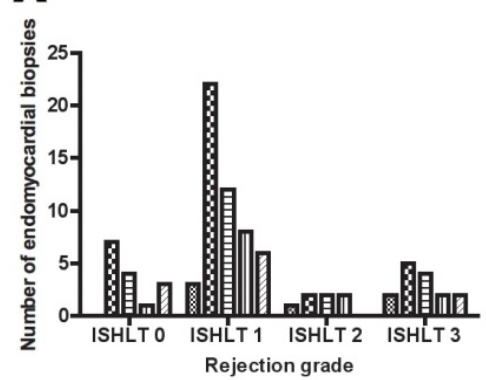

B

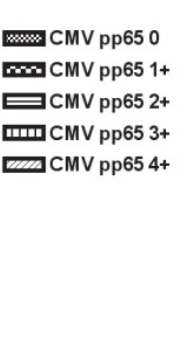

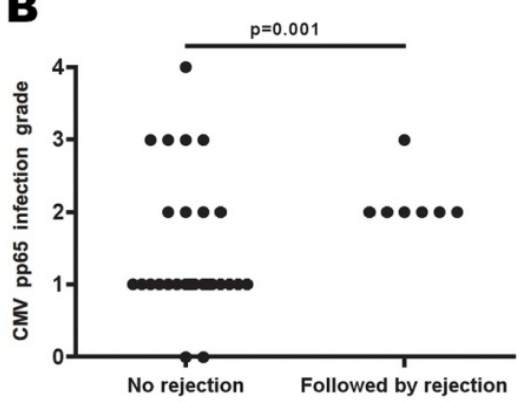

Figure 2. The degree of CMV pp65 positivity was not statistically different between the different ISHLT rejection grade groups (A). In patients where sequential biopsies were available higher CMV pp65 levels were more frequently observed in biopsies taken prior to an acute rejection episode when compared with biopsies not followed by an acute rejection episode (B).

active CMV infection in $>90 \%$ of heart transplant patients, in whom CMV DNA was detected in polymorphonuclear leukocytes despite antiviral prophylaxis [5]. These observed differences in the prevalence of CMV infection amongst various studies clearly reflects the different methods used, and most likely explain why the virus has been difficult to detect in the graft.

Presence of CMV intra-graft infection may be harmful to the graft and may also lead to a clinical CMV infection. CMV infection increases the risk for long-term complications, such as acute and chronic graft rejection, cardiovascular disease, post-transplant diabetes, and malignancies. In heart transplant patients, CMV increases the risk for transplant vascular pathology $[12,13]$. Moreover, heart transplant patients who are positive for CMV IgG and IgM have thicker plaques and more advanced calcified lesions [13]. In addition, CMV pp65 antigenemia is associated with lumen loss at 12 months after transplantation [4]. Aggressive prophylaxis against CMV, including addition of CMV immunoglobulin to antiviral prophylaxis, reduced the number of rejection episodes in heart transplant patients $[6,14]$, whereas pre-emptive treatment against CMV prevents CMV disease but not acute rejection in solid organ transplant recipients $[15,16]$. In analogy with this addition of CMV immunoglobulin to antiviral prophylaxis has been shown to reduce the risk of bronchiolitis obliterans in lung transplant recipients [17].

Early T-cell control of asymptomatic CMV replication prevents CMV viremia, acute rejection, and coronary artery lumen loss [18]. Importantly, control of CMV infection also improves long-term graft outcome. Patients receiving prophylaxis against CMV have a significantly lower incidence of chronic rejection at 5 years after transplantation [19]. Thus, CMV is a very common pathogen that places heart transplant patients at high risk for complications.

In our study, CMV pp65 levels did not correlate with rejection grade but patients experiencing an acute rejection had more often higher levels of CMV pp65 in their graft prior to an acute rejection episode $(\mathrm{p}=0.001)$. In transplant patients, monitoring of CMV pp65antigenemia results in earlier initiation of antiviral treatment than monitoring of CMV DNAemia [20]. Our findings support the notion that CMV pp65, a matrix protein found in viral particles, is an early sign of an active CMV infection affecting the graft. Additional studies of more patients, with more frequent endomyocardial biopsies, are needed to confirm that presence of high levels of CMV pp65 in endomyocardial biopsies can identify patients at high risk of rejection episodes at an early stage.

The CMV serological status of our patients was not available, but all received CMV prophylaxis for 28 days after transplantation.
Nevertheless, the effects of antiviral treatment on the intragraft CMV infection in our study are unclear. Although CMV prophylaxis reduces acute disease and CMV replication, subclinical CMV infection remains [5]. Our findings support that viral treatment does not eradicate intragraft $\mathrm{CMV}$ infections.

Numerous studies support a role for CMV infection in CAV. Nevertheless, several clinical and experimental studies have also failed to confirm the association between CMV infection and CAV and therefore the role of CMV infection in this process remains inconclusive. Our findings suggest that the difficulty of linking CMV to CAV may reflect differences in the methods used to detect CMV in tissue samples and that direct effects of CMV may be involved in cardiac allograft damage. The complexity of allograft rejection and the impact of immunosuppressive drugs and CMV infection on that process require further elucidation.

In summary, using immunohistochemistry, we found that the vast majority of cardiac transplant patients have CMV pp65 in the cardiac allograft and that the presence of high levels of CMV pp65 precedes acute rejection episodes. Further studies are needed to evaluate the clinical value of using immunohistochemistry for CMV pp65 to monitor heart transplant patients.

\section{Acknowledgments}

This work was supported by grants from the Swedish Heart-Lung Foundation (20130644, 20150677), the Swedish Medical Research Council (K2013-57X-12615-16-5), Karolinska Institutet, and the Goljes Foundation. Part of this work was presented at the XXII International Congress of the Transplantation Society, 10-14 August 2008, Sydney, Australia. All other authors declare no conflicts of interest.

\section{References}

1. Söderberg-Nauclér C (2006) Does cytomegalovirus play a causative role in the development of various inflammatory diseases and cancer? J Intern Med 259: 219246. [Crossref]

2. Fishman JA (2007) Infection in solid-organ transplant recipients. N Engl J Med 357 2601-2614. [Crossref]

3. Stern-Ginossar N, Weisburd B, Michalski A, Le VT, Hein MY, et al. (2012) Decoding human cytomegalovirus. Science 338: 1088-1093. [Crossref]

4. Potena L, Grigioni F, Ortolani P, Magnani G, Marrozzini C, et al. (2003) Relevance of cytomegalovirus infection and coronary-artery remodeling in the first year after heart transplantation: a prospective three-dimensional intravascular ultrasound study. Transplantation 75: 839-843. [Crossref]

5. Potena L, Holweg CT, Vana ML, Bashyam L, Rajamani J, et al. (2007) Frequent occult infection with Cytomegalovirus in cardiac transplant recipients despite antiviral prophylaxis. J Clin Microbiol 45: 1804-1810. [Crossref] 
6. Potena L, Holweg CT, Chin C, Luikart H, Weisshaar D, et al. (2006) Acute rejection and cardiac allograft vascular disease is reduced by suppression of subclinical cytomegalovirus infection. Transplantation 82: 398-405. [Crossref]

7. Streblow DN, Orloff SL, Nelson JA (2007) Acceleration of allograft failure by cytomegalovirus. Curr Opin Immunol 19: 577-582. [Crossref]

8. Troxell ML, Lanciault C (2016) Practical Applications in Immunohistochemistry: Evaluation of Rejection and Infection in Organ Transplantation. Arch Pathol Lab Med. [Crossref]

9. Dzabic M, Rahbar A, Yaiw KC, Naghibi M, Religa P, et al. Intragraft cytomegalovirus protein expression is associated with reduced renal allograft survival. Clin Infect Dis 53: 969-976. [Crossref]

10. Billingham ME, Cary NR, Hammond ME, Kemnitz J, Marboe C, et al. (1990) A working formulation for the standardization of nomenclature in the diagnosis of heart and lung rejection: Heart Rejection Study Group. The International Society for Heart Transplantation. J Heart Transplant 9: 587-593. [Crossref]

11. Söderberg C, Larsson S, Bergstedt-Lindqvist S, Möller E (1993) Definition of subset of human peripheral blood mononuclear cells that are permissive to human cytomegalovirus infection. J Virol 67: 3166-3175. [Crossref]

12. Grattan MT, Moreno-Cabral CE, Starnes VA, Oyer PE, Stinson EB, et al. (1989) Cytomegalovirus infection is associated with cardiac allograft rejection and atherosclerosis. JAMA 261: 3561-3566. [Crossref]

13. Fateh-Moghadam S, Bocksch W, Wessely R, Jäger G, Hetzer R, et al. (2003) Cytomegalovirus infection status predicts progression of heart-transplant vasculopathy. Transplantation 76: 1470-1474. [Crossref]
14. Rea F, Potena L, Yonan N, Wagner F, Calabrese F (2016) Cytomegalovirus Hyper Immunoglobulin for CMV Prophylaxis in Thoracic Transplantation. Transplantation 100 Suppl 3: S19-26. [Crossref]

15. Strippoli GF, Hodson EM, Jones C, Craig JC (2006) Pre-emptive treatment for cytomegalovirus viraemia to prevent cytomegalovirus disease in solid organ transplant recipients. Cochrane Database Syst Rev 2006: CD005133. [Crossref]

16. Reischig T, Jindra P, Hes O, Svecová M, Klaboch J, et al. (2008) Valacyclovir prophylaxis versus preemptive valganciclovir therapy to prevent cytomegalovirus disease after renal transplantation. Am J Transplant 8: 69-77. [Crossref]

17. Wilkens H, Sester M (2016) Treatment of Cytomegalovirus Infection with Cidofovir and CMV Immune Globulin in a Lung Transplant Recipient. Case Rep Transplant 2016: 4560745. [Crossref]

18. Tu W, Potena L, Stepick-Biek P, Liu L, Dionis KY, et al. (2006) T-cell immunity to subclinical cytomegalovirus infection reduces cardiac allograft disease. Circulation 114: 1608-1615. [Crossref]

19. Valantine HA, Gao SZ, Menon SG, Renlund DG, Hunt SA, et al. (1999) Impact of prophylactic immediate posttransplant ganciclovir on development of transplant atherosclerosis: a post hoc analysis of a randomized, placebo-controlled study. Circulation 100: 61-66. [Crossref]

20. Gerna G, Baldanti F, Torsellini M, Minoli L, Viganò M, et al. (2007) Evaluation of cytomegalovirus DNAaemia versus pp65-antigenaemia cutoff for guiding preemptive therapy in transplant recipients: a randomized study. Antivir Ther 12: 63-72. [Crossref]

Copyright: (C)2016 Dzabic M. This is an open-access article distributed under the terms of the Creative Commons Attribution License, which permits unrestricted use, distribution, and reproduction in any medium, provided the original author and source are credited. 